\title{
Is there a Normal Blood Pressure in Neonates?
}

\section{Thiel $\mathbf{M}^{\star}$}

Pediatrician, neonatologist, a doctor of naturopathy chief physician of the Clinic for children and adolescents, Sana-Klinikum Remscheid GmbH Academic Teaching Hospital of the University of Cologne Straße 21142859 Remscheid, Denmark

*Corresponding author: Dr. Michael T Thiel, Pediatrician, neonatologist, a doctor of naturopathy chief physician of the Clinic for children and adolescents, SanaKlinikum Remscheid GmbH Academic Teaching Hospital of the University of Cologne Straße 21142859 Remscheid, Denmark, Tel: +49 2191 13 5400; E-mail: michaelt.thiel@sana.de

Received date: August 25, 2015; Accepted date: August 28, 2015; Published date: September 4, 2015

Copyright: $\odot 2015$ Thiel M. This is an open-access article distributed under the terms of the Creative Commons Attribution License, which permits unrestricted use, distribution, and reproduction in any medium, provided the original author and source are credited.

\section{Editorial}

Blood pressure is normal if systemic organ perfusion is normal. So far, so good. In neonates, however, the specific risks of low organ perfusion have an impact not only on their present state, but also on their development. Inadequate perfusion of the brain can lead to intraventricular hemorrhage or periventricular leucomalacia, both disturbing the neurological development. The same is true for the gut, with consecutive necrotizing enterocolitis and other deleterious effects on the child [1-3]. For these reasons, the correlation between the neurodevelopmental outcome and the mean arterial blood pressure and (as an additional parameter) the regional cerebral oxygenation is the subject of recent research that aims to find a clinically helpful strategy.

But what is the correct method to measure blood pressure in neonates, especially in preterms, and what is the range that can be considered "normal"? Which values measured in which time slot can induce which kind of damage? And why is it so difficult to conduct evidence-based studies? There is no short answer to these questions [4]. Many studies are retrospective, others have heterogeneous or small study groups. Moreover, the methods of measuring blood pressure are not always comparable [5]. It is interesting that adults who were born as preterms (especially those with a very low birth weight) have a higher blood pressure later in life compared to those born at term. However, as therapy has changed over time in so many ways that the basic situation cannot be compared, the results of studies on adults who were born as preterms may not be readily taken into account for neonates today.

At least for preterms below $1000 \mathrm{~g}$ or 31 weeks, the classical and clinically used normal lower limit of medium arterial blood pressure is equal to the gestational age in completed weeks. According to other authors, $30 \mathrm{mmHG}$ is the lower limit that also marks the cut-off value for intervention. But a systematic proof of these guideline values has never been furnished [6-8].

An important aspect of the special circumstances of blood pressure regulation in preterms is the fact that left ventricular ejection fraction is different than in adults, while at the same time the peripheral resistance is lower. Thus, echocardiography is the most common additional method to evaluate blood pressure and perfusion. But unfortunately, the situation easily gets confusing as soon as specific conditions like a persistent arterial duct, the pulmonary situation (i.e. respiratory distress syndrome), the application of surfactant and - last but not least - the day of life are taken into account. It gets even more intricate when parameters such as blood volume, rheology, myocardial contractility and vascular resistance are taken into consideration, too.
Measurement is performed invasively, i.e. by arterial catheter, which is regarded as the gold standard, or non-invasively, i.e. by oscillometry. The overall reliability seems to be good - except for the lower limits. Unfortunately, this is the most crucial range.

Consequently, a "normal" blood pressure is defined by multimodal clinical aspects and very few paraclinical and apparative tools rather than by specific values. Most important is the overall clinical stability of the infant: Spontaneous breathing, food tolerance, normal neurological findings and a normal capillary refill will usually lead to acceptance of lower blood pressure. But on the other hand, symptoms are not always obvious: They can be too mild to be related to blood pressure anomalies, but they can also be late signs (e.g. neurological problems or reduced food tolerance) [9].

Another parameter that is commonly used to assess blood pressure is diuresis. But since there is no reliable correlation between diuresis and renal perfusion, this otherwise helpful indicator has to be judged critically as well (of course it is not forbidden to take the diuresis into account to create a complete picture of circulation in the premature infant). The same is true for additional measurements of lactate since the results are too unspecific: Although it can be caused by an impaired microcirculation, there are other possible reasons for elevated lactate.

From a therapeutical point of view, the first step in order to ensure normal microcirculation and organ perfusion is volume application, usually normal saline solution in adequate dosage. Dopamine and dobutamine are the first drugs used, but their effects on neonates may be different from those on adults due to differences in receptor concentration and responsiveness. There are some hints that the application of catecholamines may even be counterproductive with regard to the neurodevelopmental outcome because it can reduce organ perfusion. But on the other hand, there is no evidence that preterms with low arterial blood pressure have a worse outcome unless they have other significant problems.

As a consequence, a universally valid answer that is appropriate for all preterms in all conditions cannot be given. Nevertheless, studies on specific situations should be undertaken at least to avoid an unnecessary or even a negative therapy. This approach is very specific to neonatology and has formerly proven to be beneficial for its most vulnerable patient group.

\section{References}

1. Alderliesten T, Lemmers PM, van Haastert IC, de Vries LS, Bonestroo $\mathrm{HJ}$, et al. (2014) Hypotension in preterm neonates: low blood pressure alone does not affect neurodevelopmental outcome. J Pediatr 164: 986-991. 
2. Batton B, Li L, Newman NS, Das A, Watterberg KL, et al. (2013) Use of antihypotensive therapies in extremely preterm infants. Pediatrics 131(6): 1865-73.

Sipola-Leppänen M, Vääräsmäki M, Tikanmäki M, Hovi P, Miettola S, et al. (2014) Cardiovascular risk factors in adolescents born preterm. Pediatrics 134: e1072-e1081.

3. Sipola-Leppänen $M$, Karvonen R, Tikanmäki M, Matinolli HM, Martikainen S, et al. (2015) Ambulatory blood pressure and its variability in adults born preterm. Hypertension 65: 615-621.

4. Sipola-Leppänen $M$, Vääräsmäki $M$, Tikanmäki $M$, Matinolli HM, Miettola S, et al. (2015) Cardiometabolic risk factors in young adults who were born preterm. Am J Epidemiol 181: 861-873.

5. Barr PA, Bailey PE, Sumners J, Cassady G (1977) Relation between arterial blood pressure and blood volume and effect of infused albumin in sick preterm infants. Pediatrics 60: 282-289.
6. Stranak Z, Semberova J, Barrington K, O'Donnell C, Marlow N, et al. (2014) International survey on diagnosis and management of hypotension in extremely preterm babies. Eur J Pediatr 173: 793-798.

7. Edwards MO, Watkins WJ, Kotecha SJ, Halcox JP, Dunstan FD, et al. (2014) Higher systolic blood pressure with normal vascular function measurements in preterm-born children. Acta Paediatr 103: 904-912.

8. Takci S, Yigit S, Korkmaz A, Yurdakök M (2012) Comparison between oscillometric and invasive blood pressure measurements in critically ill premature infants. Acta Paediatr 101: 132-135.

9. Stopfkuchen H (2003) What is a Sufficient Blood Pressure in the Preterm Newborn? Klin Pediatrics 215: 16-21. 